Jurnal Ilmiah Matematika dan Pendidikan Matematika (JMP)

Vol. 10 No. 2, Desember 2018, hal. 31-42

ISSN (Cetak) : 2085-1456; ISSN (Online) : 2550-0422

\title{
KEMAMPUAN PENALARAN BERDASARKAN \\ KEYAKINAN MATEMATIKA DALAM PEMBELAJARAN PBL MELALUI PENDEKATAN INTERAKSI DYADIC
}

\author{
Dyah Retno Kusumawardani
}

\author{
SMA IT Al Irsyad Al Islamiyyah Purwokerto \\ dyahhh.ajah@gmail.com
}

\begin{abstract}
The purposes of this research were (1) to describe the learning quality of $P B L$ through dyadic interaction approach to mathematical reasoning ability of grade $X$ students of IT Al Irsyad Purwokerto High School (2) to find pattern of students reasoning ability based on mathematical belief. This study uses a mixed method. Data analysis started from the analysis of test items. The analysis uses the prerequisite test and then hypothesis testing uses rara average ( $t$-test), then the proportion of comparative tests (test-z) is to calculate the classical completeness. Further testing of determining the difference between the two classes uses different test average (t-test right side). Qualitative data analysis uses qualitative description. The results of quantitative research shows that learning class with PBL and dyadic interaction approach reached classical total $80 \%$. The average difference test showed class' results with PBL dyadic interaction approach better than a class activity with PBL. Subjects with very low belief can only fulfill 1 reasoning indicator well. Subjects with low belief can fulfill 3 reasoning indicators well and have not been able to fulfill 1 other indicator. Subjects with high belief can fulfill 4 indicators where 1 indicator is imperfect and subject with very high belief can fulfill all the indicators of reasoning well and complete.
\end{abstract}

Keywords: Mathematical reasoning, belief, problem based learning, dyadic interaction.

\begin{abstract}
ABSTRAK. Tujuan penelitian untuk (1) mendeskripsikan kualitas pembelajaran PBL melalui pendekatan interaksi dyadic terhadap kemampuan penalaran matematis siswa kelas X SMA IT Al Irsyad Purwokerto (2) menemukan pola kemampuan penalaran siswa berdasarkan keyakinan matematika. Penelitian ini menggunakan metode kombinasi. Analisis data dimulai dari analisis butir soal tes uji coba kemudian analisis uji prasyarat. Pengujian hipotesis menggunakan uji rara-rata (uji-t), kemudian uji banding proporsi (ujiz) untuk menghitung ketuntasan klasikal. Selanjutnya pengujian untuk mengetahui perbedaan antara 2 kelas menggunakan uji beda rata-rata (uji-t pihak kanan). Analisis data kualitatif menggunakan metode deskriptif kualitatif. Hasil penelitian kuantitatif menunjukkan bahwa kelas dengan pembelajaran PBL dengan pendekatan interaksi dyadic mencapai tuntas klasikal $80 \%$. Uji beda rata-rata menunjukkan hasil kelas dengan pembelajaran PBL melalui pendekatan interaksi dyadic lebih baik dari kelas dengan pembelajaran PBL. Subjek dengan keyakinan sangat rendah hanya dapat memenuhi 1 indikator penalaran dengan baik. Subjek dengan keyakinan rendah dapat memenuhi 3 indikator penalaran dengan baik dan belum dapat memnuhi 1 indikator yang lain. Subjek dengan keyakinan tinggi dapat memenuhi 4 indikator dimana 1 indikator belum sempurna dan subjek dengan keyakinan sangat tinggi dapat memenuhi semua indikator penalaran dengan baik dan lengkap.
\end{abstract}

Kata Kunci: Penalaran matematis, keyakinan, problem based learning, interaksi dyadic. 


\section{PENDAHULUAN}

Matematika adalah suatu alat untuk mengembangkan cara berpikir (Hudojo, 2003) Matematika terbentuk sebagai hasil pemikiran manusia yang berhubungan dengan ide, proses, dan penalaran. Mata pelajaran matematika perlu diberikan kepada semua siswa sebagai dasar meningkatkan kemampuan berpikir logis, analisis, sistematis, kritis serta kemampuan bekerja (Depdiknas, 2006). Hal ini senada dengan pendapat Prabawa dan Zaenuri (2017), bahwa Matematika mempunyai peranan penting dalam perkembangan ilmu pengetahuan dan teknologi, baik sebagai alat bantu dalam penerapan pada disiplin ilmu lain maupun sebagai sarana berpikir logis, analitis, kreatif dan sistematis.

Menyadari arti pentingnya matematika tersebut, maka matematika dirasakan perlu untuk dipahami dan dikuasai oleh segenap lapisan masyarakat, terutama siswa-siswa sekolah dasar hingga perguruan tinggi. Kemampuan matematika siswa di Indonesia rendah diketahui dari hasil evaluasi TIMSS 2015. Berdasarkan survei Internasional tersebut, rata-rata skor prestasi matematika siswa di Indonesia masih berada signifikan di bawah rata-rata Internasional. Rata-rata persentase yang paling rendah yang dicapai oleh peserta didik Indonesia adalah pada domain kognitif pada level penalaran (reasoning) yaitu 20\%. Rendahnya kemampuan matematika peserta didik pada domain penalaran perlu mendapat perhatian (Fauziyah, Isnarto, \& Mariani, 2017).

Rendahnya prestasi siswa dalam matematika selain dipengaruhi oleh aspek kognitif, dapat juga dipengaruhi oleh aspek afektif. Salah satu aspek afektif yang mempengaruhi prestasi matematika adalah keyakinan (Sumpter, 2013). Keyakinan dapat menjadi pengaruh positif saat siswa tidak mengetahui bagaimana menyelesaikan permasalahan matematika. Keyakinan matematika menurut Sumpter (2013) adalah pemahaman dan perasaan seseorang yang membentuk cara seseorang mengkonseptualisasi dan berperan aktif dalam perilaku matematika yang mendorong dan muncul sebagai sebuah cara berpikir didalam pikirannya. Berdasarkan definisi tersebut, diketahui bahwa keyakinan akan mendorong 
seseorang untuk berperan aktif dalam perilaku matematika termasuk penalaran matematika.

Penalaran dianggap sebagai proses matematis menarik kesimpulan berdasarkan bukti atau asumsi (NCTM, 2000). Penalaran juga dapat dipandang sebagai proses berpikir (thinking process), hasil (product) dari proses berpikir, atau keduanya (Lithner, 2008). Selain itu, penalaran matematika adalah penalaran tentang dan dengan objek matematika (Brodie, 2010). Berdasarkan uraian diatas dapat disimpulkan bahwa penalaran matematika adalah penalaran tentang dan dengan objek matematika yang merupakan proses berpikir atau hasil dari proses berpikir yang diperlukan untuk menarik kesimpulan atau membuat suatu pernyataan baru yang benar berdasarkan pada beberapa pernyataan yang kebenarannya telah dibuktikan atau diasumsikan sebelumnya.

Penalaran dan matematika tidak dapat dipisahkan satu sama lain karena dalam menyelesaikan permasalahan matematika memerlukan penalaran sedangkan kemampuan penalaran dapat dilatih dengan belajar matematika. Kemampuan untuk bernalar menjadikan siswa dapat memecahkan masalah dalam kehidupannya, di dalam dan di luar sekolah (Junaedi \& Asikin, 2012). Model pembelajaran yang dapat digunakan untuk memfokuskan siswa pada kemampuan penalaran matematis adalah model pembelajaran PBL atau Problem Based Learning. PBL merupakan salah satu model pembelajaran yang digunakan untuk meningkatkan level berpikir tinggi yang diorientasikan pada masalah, termasuk belajar bagaimana belajar (Arends, 1997). Salah satu kemampuan dalam level berpikir tingkat tinggi adalah kemampuan penalaran (Madu, 2017). Oleh karena itu, model PBL dapat digunakan dalam pembelajaran yang memfokuskan pada kemampuan penalaran siswa.

Belajar merupakan suatu kegiatan yang dilakukan dalam interaksi dengan lingkungan sosial maupun fisik (Sugihartono, 2007). Proses belajar harus dirancang untuk memberikan pengalaman belajar yang melibatkan proses mental dan fisik melalui interaksi antar-siswa, siswa dengan guru, lingkungan, dan sumber belajar lainnya dalam rangka pencapaian kompetensi dasar (Kartono, 2010). Kegiatan pembelajaran membutuhkan interaksi dengan orang-orang di 
sekitar, seperti antara siswa dan guru, siswa dan siswa, sehingga dalam pembelajaran perlu diterapkan pendekatan pembelajaran. Tipe pendekatan yang digunakan dalam penelitian ini adalah pendekatan interaksi dyadic. Interaksi dyadic dipandang sebagai proses dimana pengetahuan dibangun secara sosial. Pendekatan interaksi dyadic, yang mana ciri khas dari pendekatan pembelajaran ini adalah melibatkan dua orang siswa dalam penyampaian materi. Pendekatan interaksi dyadic dapat digunakan sebagai salah satu alternatif proses pembelajaran yang menghasilkan kemampuan penalaran yang lebih baik (Mellone, 2017).

Permasalahan dalam penelitian ini adalah (1) bagaimana kualitas pembelajaran PBL melalui pendekatan interaksi dyadic terhadap kemampuan penalaran matematis siswa kelas X SMA IT Al Irsyad Purwokerto?, dan (2) bagaimana kemampuan penalaran siswa berdasarkan keyakinan matematika pada pembelajaran PBL melalui pendekatan interaksi dyadic?

\section{METODE PENELITIAN}

Penelitian ini merupakan jenis penelitian kombinasi kualitatif dan kuantitatif. Desain yang digunakan dalam penelitian ini adalah desain concurrent embedded. Desain ini dapat dicirikan sebagai strategi metode campuran yang menerapkan satu tahap pengumpulan data kuantitatif dan kualitatif dalam satu waktu dimana penelitian kualitatif sebagai metode primer sedangkan penelitian kuantitatif sebagai mentode sekunder. Pada penelitian ini ada tiga tahap penelitian dimana penelitian diawali studi pendahuluan dalam rangka mengidentifikasikan masalah-masalah di lapangan dengan melakukan kajian pada data-data, wawancara dengan guru, dan kajian-kajian pada literatur. Pada tahap studi pendahuluan ditemukan suatu masalah yang kemudian diteliti melalui serangkaian penelitian kuantitatif dan kualitatif pada tahap dua.

Pada tahap dua, peneliti memberikan intervensi (perlakuan) kepada siswa menggunakan pembelajaran PBL dengan pendekatan interaksi dyadic. Pada tahap ini peneliti memperoleh data kualitatif berupa kualitas pelaksanaan pembelajaran. Pada penelitian kuantitatif pada tahap 2, penelitian yang digunakan adalah penelitian eksperimen dengan desain quasi experimental, yaitu desain penelitian 
yang melibatkan dua kelompok (eksperimen dan kontrol) di mana pemilihan kedua kelompok tersebut tidak dipilih secara random. Pada kelompok eksperimen diberi perlakuan sementara kelompok kontrol tidak diberi perlakuan. Keduanya diberi pretes dan postes yang berfungsi untuk mengetahui apakah ada peningkatan dari keadaan awal dan akhir kedua kelompok. Quasi experimental design yang dipilih pada penelitian kuantitatif ini adalah Nonrandomized Control Group Pretest-Postest Design.

Populasi dalam penelitian ini adalah siswa kelas X MIPA SMA IT Al Irsyad Al Islamiyyah Purwokerto semester genap tahun pelajaran 2017/2018. Dari enam kelas X MIPA SMA IT Al Irsyad Al Islamiyyah Purwokerto dipilih dua kelas sebagai sampel penelitian, yaitu kelas eksperimen yang menerapkan model pembelajaran PBL dengan pendekatan interaksi dyadic dan kelas kontrol yang menerapkan model pembelajaran PBL. Penentuan sampel penelitian berdasarkan berdasarkan petimbangan peneliti dan guru. Untuk mengetahui kelas tersebut dalam kondisi awal yang sama perlu diadakan beberapa uji prasyarat, antara lain uji normalitas, uji homogenitas, dan uji kesamaan rata-rata.

Data yang digunakan sebagai uji prasyarat dalam pemilihan sampel adalah data hasil pretes materi prasyarat. Angket keyakinan matematika diberikan sebelum penelitian. Subjek penelitian diambil dari peserta didik kelas eksperimen berdasarkan angket keyakinan matematika, selanjutnya dikonsultasikan dengan guru kelas, dipilihlah dua siswa yang memiliki keyakinan matematika sangat tinggi, dua siswa yang memiliki keyakinan matematika tinggi, dua siswa yang memiliki keyakinan matematika rendah dan dua siswa yang memiliki keyakinan matematika sangat rendah yang akan dianalisis kemampuan penalarannya.

Sumber data dalam penelitian ini adalah lembar jawaban tes kemampuan penalaran matematis (TKPM), angket keyakinan matematika, lembar hasil wawancara peserta didik, dan observasi kualitas pembelajaran. TKPM diberikan dua kali yaitu pre test dan post test. TKPM dilakukan pada kelas eksperimen dan kelas kontrol. Jawaban peserta didik pada TKPM dianalisis dan subjek penelitian diwawancarai. Data yang diperoleh diuji menggunakan uji normalitas, uji homogenitas, uji kesamaan rata-rata, uji ketuntasan, uji beda rata-rata dan uji 
peningkatan keyakinan matematika. Sedangkan analisis data kualitatif dilakukan dengan cara mereduksi data, menyajikan data, dan menarik kesimpulan dari data yang telah dikumpulkan dan memverifikasi kesimpulan tersebut.

\section{HASIL DAN PEMBAHASAN}

Hasil penelitian secara kualitatif adalah hasil penelitian yang meliputi kualitas pembelajaran secara kualitatif dan data angket keyakinan matematika. Kualitas pembelajaran merupakan serangkaian kegiatan yang dapat meningkatkan kompetensi siswa (Hightower et al., 2011). Kualitas pembelajaran diukur dari 3 tahap yaitu (1) perencanaan (planning and preparation), (2) pelaksanaan (classroom environtmen dan instruction), (3) penilaian (profesional responsibility).

Kualitas pembelajaran secara kualitatif meliputi tahap perencanaan dan tahap pelaksanaan. Pada tahap perencanaan peneliti membuat perangkat pembelajaran meliputi silabus, RPP, buku siswa, dan LKS yang divalidasi oleh 3 validator ahli. Hasil penilaian setiap validator terhadap perangkat pembelajaran dapat dilihat pada Tabel 1.

Tabel 1 Hasil Perolehan Penilaian Perangkat Pembelajaran

\begin{tabular}{|c|c|c|c|c|c|}
\hline \multirow[t]{2}{*}{ Instrument } & \multicolumn{3}{|c|}{$\begin{array}{l}\text { Rata-rata } \\
\text { Validator }\end{array}$} & \multirow{2}{*}{$\begin{array}{l}\text { Rata- } \\
\text { rata } \\
\text { Total }\end{array}$} & \multirow[t]{2}{*}{ Kategori } \\
\hline & V001 & V002 & V003 & & \\
\hline Silabus & 4,00 & 4,00 & 4,22 & 4,07 & Baik \\
\hline RPP & 4,17 & 4,00 & 4,13 & 4,10 & Baik \\
\hline Buku Siswa & 4,13 & 4,00 & 4,00 & 4,04 & Baik \\
\hline LKS & 4,11 & 4,00 & 4,22 & 4,11 & Baik \\
\hline
\end{tabular}

Berdasarkan Tabel 1, hasil perolehan penilaian perangkat pembelajaran diperoleh rata-rata nilai untuk silabus, RPP, Buku Siswa, dan LKS masuk dalam kategori baik. Berdasarkan penilaian validator ahli tersebut, perangkat yang telah dibuat oleh peneliti layak untuk digunakan dalam penelitian.

Pada tahap pelaksanaan, pengukuran kualitas pelaksanaan pembelajaran dilakukan dengan mengamati kualitas pembelajaran dan keterlaksanaan pembelajaran. Pelaksanaan pembelajaran dikatakan berkualitas apabila hasil 
pengamatan kualitas dan keterlaksanaan pembelajaran minimal masuk pada kategori baik. Nilai rata-rata untuk pengamatan kualitas pembelajaran dan keterlaksanaan pembelajaran dari pertemuan pertama sampai terakhir dapat diketahui bahwa keterlaksanaan pembelajaran termasuk kategori baik, sehingga dapat disimpulkan bahwa kemampuan peneliti dalam persiapan dan mengelola pembelajaran termasuk dalam kategori baik.

Penilaian kualitas pembelajaran yang terakhir yaitu pada tahap penilaian. Penilaian pembelajaran secara kualitatif dilakukan dengan memberikan angket respon siswa terhadap pembelajaran yang telah dilakukan. Berdasarkan angket respon siswa menunjukkan bahwa mayoritas siswa menilai pembelajaran yang telah dilaksanakan dengan baik.

Hasil penelitian secara kuantitatif adalah data kualitas pembelajaran pada tahap penilaian. Penilaian pembelajaran secara kuantitatif berdasarkan data awal dan data akhir tes kemampuan penalaran. Data awal peserta didik kelas eksperimen dan kelas kontrol diperoleh dari rata-rata nilai pretes materi prasyarat. Rata-rata nilai pretes kelas eksperimen adalah 74,32 dan rata-rata nilai pre test kelas kontrol adalah 70,57. Berdasarkan uji normalitas dengan bantuan SPSS menggunakan uji Kolmogorof-Smirnov dengan taraf nyata 5\%, data awal kelas eksperimen dan kelas kontrol berdistribusi normal. Berdasarkan uji homogenitas dengan bantuan SPSS menggunakan uji Levene's Test dengan taraf nyata 5\%, varians kelas eksperimen sama dengan varians kelas kontrol. Berdasarkan uji kesamaan rata-rata dengan bantuan SPSS menggunakan Independent Sample TTest dengan taraf nyata 5\%, rata-rata data awal siswa kelas eksperimen sama dengan rata-rata data awal siswa kelas kontrol.

Data akhir kemampuan penalaran matematis diperoleh dari postes soal tes kemampuan penalaran matematis. Rata-rata hasil nilai postes dari TKPM kelas eksperimen adalah 86,08 sementara ratarata nilai post test dari TKPM kelas kontrol sebesar 75,50. Berdasarkan uji normalitas dengan SPSS menggunakan uji Kolmogorof-Smirnov dengan taraf nyata 5\%, hasil nilai postes TKPM kelas eksperimen dan nilai post test kelas kontrol berdistribusi normal. 
Hasil nilai postes TKPM siswa pada kelas eksperimen diperoleh nilai terendah adalah 76 dan nilai tertinggi adalah 95, sedangkan nilai KKM adalah 80. Jumlah peserta didik yang tuntas adalah 24 siswa. Dari perhitungan diperoleh $z_{\text {hitung }}=2,00$, sedangkan dengan $\alpha=5 \%$ diperoleh $z_{\text {tabel }}=1,64$. Karena $Z_{\text {hitung }}=$ 2,00 $>z_{\text {tabel }}=1,64$ maka $\mathrm{H}_{0}$ diterima, artinya proporsi hasil belajar siswa kelas eksperimen yang dikenai PBL dengan pendekatan interaksi dyadic telah mencapai $80 \%$.

Berdasarkan hasil perhitungan uji beda rata-rata diperoleh thitung $=1,94$ dengan taraf signifikansi $5 \%$ dan $\mathrm{dk}=51$ diperoleh nilai ttabel $=1,67$. Karena $t_{\text {hitung }}>\mathrm{t}_{\text {tabel }}$, dapat disimpulkan bahwa kemampuan penalaran matematis siswa pada kelas eksperimen lebih baik daripada kemampuan penalaran matematis siswa pada kelas kontrol. Dengan demikian, pembelajaran dengan model PBL melalui pendekatan interaksi dyadic dapat dikatakan berkualitas.

Pembelajaran model PBL yang berkualitas juga tidak terlepas dari kegiatan pada saat proses pembelajaran. model PBL yang digunakan dalam penelitian ini menggunakan pendekatan interaksi dyadic. Model PBL mendorong siswa agar mampu mengarahkan dirinya sendiri dalam belajar pada motivasi yang lebih tinggi, ingatan materi yang lebih baik, perkembangan dalam bernalar dan ketrampilan menyelesaikan masalah, serta mengembangkan pemahaman yang lebih baik pada siswa dari proses kelompok dan kebutuhan ketrampilan demi suksesnya kerjasama kerja (Ball dan Pelco, 2006). Model PBL dapat mengorganisasikan siswa menjadi kelompok-kelompok dalam pembelajaran. Model PBL dengan pendekatan interaksi dyadic, menjadikan interaksi antar siswa dalam kelompok lebih maksimal sehingga mampu meningkatkan kemampuan penalaran matematisnya.

Pada saat proses pembelajaran, siswa dikelompokan menjadi kelompok PBL untuk mendiskusikan suatu permasalahan. Antar anggota pada kelompok PBL tersebut dipasangkan agar terjadi proses interaksi. Interaksi ini yang merupakan interaksi dyadic, yang menghasilkan pemahaman saling timbal balik untuk meningkatkan kemampuan penalaran matematis. Hal ini sesuai dengan penelitian (Mellone, Verschaffel, \& Dooren, 2017) bahwa interaksi dyadic 
menghasilkan kemampuan penalaran yang lebih baik dibandingkan interaksi non dyadic atau pembelajaran individual.

Hasil angket keyakinan matematika siswa sebelum pembelajaran pada kelas eksperimen ditunjukan pada Tabel 2 berikut.

Tabel 2. Pengelompokkan Siswa ditinjau dari Keyakinan Matematika

\begin{tabular}{lll}
\hline Karakteristik Keyakinan & Banyaknya Siswa & Persentase \\
\hline Keyakinan sangat tinggi & 2 & $8 \%$ \\
Keyakinan tinggi & 13 & $52 \%$ \\
Keyakinan rendah & 6 & $24 \%$ \\
Keyakinan sangat rendah & 4 & $16 \%$ \\
\hline Jumlah & $\mathbf{2 5}$ & $\mathbf{1 0 0 \%}$ \\
\hline
\end{tabular}

Berdasarkan Tabel 2, dipilih dua subjek penelitian dari masing-masing karakteristik untuk dianalisis kemampuan penalaran matematisnya secara mendalam. Pada penelitian ini, pola kemampuan penalaran matematis siswa dianalisis berdasarkan keyakinan matematika siswa, dimana keyakinan matematika siswa dibedakan menjadi empat tingkatan yaitu keyakinan sangat rendah, keyakinan rendah, keyakinan tinggi dan keyakinan sangat tinggi. Pola kemampuan penalaran matematis siswa mengacu pada indikator penalaran matematis dari NCTM (2000) yaitu kemampuan menganalisis masalah, kemampuan menerapkan strategi, kemampuan mencari dan menggunakan hubungan dari domain matematika yang berbeda, konteks yang berbeda dan representasi yang berbeda dan kemampuan menafsirkan solusi dan cara menjawab masalah.

Subjek dengan keyakinan sangat rendah hanya dapat memenuhi indikator menganalisis masalah. Jawaban yang diberikan kurang tepat dan ragu-ragu dalam memberikan alasan dalam menjawab soal serta kurang yakin dalam menjawab pertanyaan wawancara. Subjek dengan keyakinan rendah belum dapat memenuhi indikator menafsirkan solusi dan cara menjawab masalah. Jawaban yang diberikan tepat namun kurang lengkap dan masih ragu-ragu dalam memberikan alasan menjawab soal serta kurang yakin dalam menjawab pertanyaan wawancara. Subjek dengan keyakinan tinggi dapat memenuhi semua indikator penalaran 
namun belum sempurna dalam menafsirkan solusi dan cara menjawab masalah. Jawaban yang diberikan tepat namun masih kurang lengkap dalam memberikan alasan menjawab soal. Pada saat wawancara lancar dalam menjawab pertanyaan. Subjek dengan keyakinan sangat tinggi dapat memenuhi semua indikator penalaran matematis. Jawaban yang diberikan tepat dan lengkap dalam memberikan alasan menjawab soal serta lancar dalam menjawab saat wawancara.

\section{KESIMPULAN DAN SARAN}

Pembelajaran PBL melalui pendekatan interaksi dyadic terhadap kemampuan penalaran matematis siswa kelas $X$ termasuk dalam kategori baik dan dapat dikatakan berkualitas. Subjek dengan keyakinan sangat rendah hanya dapat memenuhi 1 indikator penalaran dengan baik. Subjek dengan keyakinan rendah dapat memenuhi 3 indikator penalaran dengan baik dan belum dapat memnuhi 1 indikator yang lain. Subjek dengan keyakinan tinggi dapat memenuhi 4 indikator dimana 1 indikator belum sempurna dan subjek dengan keyakinan sangat tinggi dapat memenuhi semua indikator penalaran dengan baik dan lengkap.

Berdasarkan kesimpulan yang diperoleh, penggunaan model PBL melalui pendekatan interaksi dyadic dinilai berkualitas dan dapat meningkatkan kemampuan penalaran matematis siswa. Oleh karena itu, peneliti memberikan saran model PBL melalui pendekatan interaksi dyadic dapat dijadikan pilihan dalam pembelajaran yang bertujuan meningkatkan kemampuan penalaran matematis

\section{DAFTAR PUSTAKA}

Arends, R. I., Classroom Instruction and Management, the Mc.GrawHill Companies, U.S.A., 1997.

Ball, C. T. dan Pelco, L. E., Teaching Research Methods to Undergraduate Psychology Students Using an Active Cooperative Learning Approach, International Journal of Teaching and Learning in Higher Education, 17(2) (2006), 147-154. 
Brodie, K., Teaching Mathematical Reasoning in Secondary School Clasroom, Springer, New York, 2010.

Depdiknas, Kurikulum Tingkat Satuan Pendidikan, Depdiknas, Jakarta, 2006.

Fauziyah, I., Isnarto, dan Mariani, S., Kemampuan penalaran geometris siswa pada pembelajaran RME dengan penekanan hands on activity berdasarkan aktivitas belajar, Unnes Journal of Mathematics Education Research, 6(1) (2017), 30-37.

Hightower, A. M., Delgado, R. C., Llyod, S. C., Wittenstein, C. B., Sellers, K., dan Swanson, C. B., Improving Student Learning By Supporting Quality Teaching: Key Issues, Effective Strategies, Bethesda: Editorial Projects in Education, Inc., 2011.

Hudojo, Pengembangan Kurikulum dan Pembelajaran Matematika, Jurusan FMIPA UNM, Malang, 2003.

Junaedi, I. dan Asikin, M., Pengembangan Pembelajaran Matematika Humanistik untuk Meningkatkan Kemahiran Matematis, Unnes Journal of Mathematics Education Research, 1(2) (2012), 115-120.

Kartono, Hands on Activity pada Pembelajaran Geometri Sekolah sebagai Asesmen Kinerja Siswa, Jurnal Kreano, 1(1) (2010), 21-32.

Lithner, J. A., Research Framework for Creative and Imitative Reasoning, Educational Studies in Mathematics, 67(3) (2008), 255-276.

Madu, A., Higher Order Tingking Skills (Hots) in Math Learning, IOSR Journal of Mathematics, 13(5) (2017), 70-75.

Mellone, M., Verschaffel, L., dan Dooren, W. V., The Effect of Rewording and Dyadic Interaction on Realistic Reasoning in Solving Word Problems, The Journal of Mathematical Behavior, 46 (2017), 1-12.

NCTM, Assesment And Standards For School Mathematics, Reston, VA: Author, 2000.

Prabawa, E. A., dan Zaenuri, Analisis Kemampuan Pemecahan Masalah Ditinjau dari Gaya Kognitif Siswa pada Model Project Based Learning Bernuansa Etnomatematika, Unnes Journal of Mathematics Education Research, 6(1) (2017), 120-129. 
Sugihartono, Psikologi Pendidikan, UNY Press, Yogyakarta, 2007.

Sumpter, L., Themes and Interplay of Beliefs in Mathematical Reasoning, International Journal of Science and Mathematics Education, 11(5) (2013), $1115-1135$. 